\title{
Characterization of Thailand Rice Husk Ash from Biomass Power Plant and Synthesized Zeolite
}

\author{
Chawikarn Santasnachok, Winarto Kurniawan and Hirofumi Hinode \\ Tokyo Institute of Technology, Department of International Development Engineering, Tokyo 1528550, Japan
}

Received: February 25, 2014 / Accepted: March 16, 2015 / Published: March 31, 2015.

\begin{abstract}
Thailand rice husk ash was used to synthesize zeolite by hydrothermal treatment. Raw rice husk ash material and zeolitic products were characterized in terms of specific surface area (BET method), morphological analysis (SEM), mineralogical composition (XRD) and CEC (cation exchange capacity). LOI (Loss of ignition) of rice husk ash was also evaluated. Result indicated that the rice husk ash sample from Roi-Et Green power plant in the Northeastern of Thailand with combustion temperature of $650{ }^{\circ} \mathrm{C}$ has a high content of $\mathrm{SiO}_{2}$ (above $90 \mathrm{wt} . \%$ ). Zeolite-X from rice husk ash with high content of Si was successfully synthesized using hydrothermal treatment. The zeolitic material synthesized with the optimal condition possessed a maximum value of CEC of 503 $\mathrm{meq} / 100 \mathrm{~g}$, and it has potentiality to be used as ion exchangers.
\end{abstract}

Key words: Zeolite, rice husk ash, hydrothermal synthesis.

\section{Introduction}

Rice husk is well-known as an agriculture by-product of the rice milling industry. It is the most important agriculture residues in term of quantity. In Thailand, rice was cultivated not only for domestic consumption but also for export [1]. The rice husk can be used as a fuel in steam boiler to generate hot steam in the power plant [2]. If the remaining ashes from burned husks are not collected and treated properly, they could become the cause of air pollutants that affect the environment due to the small particle size and light weight. The utilization of these ashes as raw materials in cement industries or insulator in steel industries has been practiced. The study of RHA (rice husk ash) showed high content of silica and alumina similar to raw materials typically used in zeolite synthesis [3]. These raw materials can be coal fly ash $[4,5]$, oil shale ash [6], and bagasse fly ash [7]. Therefore, rice husk ash is a potential raw material for zeolite synthesis. In recent years, zeolite syntheses

Corresponding author: Chawikarn Santasnachok, Ph.D., research field: environmental engineering. E-mail: csantasnachok@gmail.com. from fly ashes have been proposed in order to obtain a pure zeolite, rather than a mixture of zeolitic materials. The most common method involves a hydrothermal process, in which the stating method, rice husk ash as a silica source was mixed an alkali solution at different condition of temperature, process and time. In this process, the formation of a particular zeolite strongly depends on the ratio of $\mathrm{SiO}_{2} / \mathrm{Al}_{2} \mathrm{O}_{3}$ in the starting material [8]. The aim of the work is to characterize rice husk ash from biomass power plant in Thailand and synthesized zeolite from it by varying temperature and heating time.

\section{Materials and Methods}

\subsection{Materials}

Raw rice husk ash obtained from Roi-Et Green power plant in the Northeastern of Thailand was used as raw material. The chemical composition of raw rice husk ash was determined by ICP-AES method using SPS 7800 (SII) and is show in Table 1. The high content of silica was confirmed from this result. Rice husk ash was sieved to remove dirt and was dried in oven at $100{ }^{\circ} \mathrm{C}$ overnight. The particle fraction was 
separated from the bulk rice husk ash by mechanical sieving using standard sieve of 25 meshes (particle size less than $0.710 \mathrm{~mm}$ ). The chemicals used in this experiment were obtained from Wako Pure Chemical Industries, Ltd., Japan.

\subsection{Silica Extraction from Rice Husk Ash}

The first preparation step after drying raw material in oven at $100{ }^{\circ} \mathrm{C}$ overnight was the extraction of silicon and aluminum content from RHA particles [7]. $10 \mathrm{~g}$ of ash was mixed with sodium hydroxide powder (Waco; 97 wt.\% $\mathrm{NaOH}$ ) with weight ratio of RHA: $\mathrm{NaOH}$ of $1: 2$ and heated at temperature of $300{ }^{\circ} \mathrm{C}$ for $1 \mathrm{~h}$. The mixture was then cooled to room temperature. The obtained powder was mixed with deionized water with weight ratio of powder to water of 1:5 followed by stirring for $2 \mathrm{~h}$ at room temperature. The solid in the mixture were then filtered to obtain a clear supernatant by using Whatman ${ }^{\mathrm{TM}}$ filter paper 540 hardened ashless. The concentrations of silicon, aluminum and sodium in the supernatant were measured with ICP-AES.

\subsection{Zeolite Synthesis from Rice Husk Ash}

Zeolite synthesis was done by hydrothermal treatment. The synthesis mixture was prepared from the high silica supernatant and sodium aluminate $\left(\mathrm{NaAlO}_{2}\right)$ solution from dissolution of sodium aluminate powder (Waco; $0.77 \mathrm{M}$ ratio of $\mathrm{Al} / \mathrm{NaOH}$ ) into deionized water. The $\mathrm{Si} / \mathrm{Al}$ molar ratio of synthesis mixture was 2.0. The amount of sodium aluminate added to the mixture was determined from the amount required to make the supernatant obtained from steps explained in section 2.2 to have $\mathrm{Si} / \mathrm{Al}$ molar of 2.0. The mixture was stirred in ultrasonic bath for $5 \mathrm{~min}$, and subsequently stirred for $1 \mathrm{~h}$ with magnetic stirring machine. After that the mixture was mixed thoroughly and treated at different temperature of $70{ }^{\circ} \mathrm{C}, 90{ }^{\circ} \mathrm{C}$ and $120^{\circ} \mathrm{C}$ for 10 to 24 in Teflon ${ }^{\mathrm{TM}}$-lined stainless steel vessels of $15 \mathrm{~mL}$ capacity without agitation. The final procedures were filtering, washing and drying of the precipitates. The nomenclature of synthesized zeolites shows in Table 2.

\subsection{Characterization of Rice Husk Ash and Zeolites}

The LOI test was done by placing $1 \mathrm{~g}$ of dried sample of the rice husk ash in a crucible and igniting in the furnace at $1000{ }^{\circ} \mathrm{C}$ for $30 \mathrm{~min}$ to achieve a constant mass left, followed by cooling at room temperature. The loss of ignition, as a percentage by mass given by the formula:

$$
L O I=\frac{M_{o}-M_{1}}{M_{o}} \times 100 \%
$$

where $M_{o}$ is the mass of the sample and $M_{l}$ is the mass of the sample after ignition.

The mineralogical composition and specific surface area of rice husk ash and zeolite samples were analyzed by XRD (X-ray diffraction) analyses (performed in Multiflex (Rigaku) with $\mathrm{Cu}-\mathrm{K} \alpha$ radiation, analysis was carried out to determine the crystalline type of zeolites produced) and BET (Brunauer-Emmett-Teller) surface area analysis using Autosorb 1 (Quantachrome), respectively.

The CEC of zeolites synthesized was measured using sodium acetate method. First, zeolite was ion exchanged with sodium acetate to exchange all the cations in the material with sodium. The sodium ion was then being extracted completely using ammonium acetate. The extracted sodium ions concentration was then be analyzed using ICP-AES.

\section{Results and Discussion}

The loss of ignition for rice husk ash is usually due to the presence of unburned carbon (indicating the burning efficiency of a thermoelectric power plant)

Table 1 The chemical composition of raw rice husk ash.

\begin{tabular}{llllllll}
\hline Composition & $\mathrm{SiO}_{2}$ & $\mathrm{Al}_{2} \mathrm{O}_{3}$ & $\mathrm{~K}_{2} \mathrm{O}$ & $\mathrm{MgO}$ & $\mathrm{Na}_{2} \mathrm{O}$ & $\mathrm{Fe}_{2} \mathrm{O}_{3}$ & Others \\
\hline wt. $\%$ & 91.50 & 2.27 & 0.48 & 1.00 & 2.68 & 0.10 & 1.97 \\
\hline
\end{tabular}


Table 2 Nomenclature of synthesized zeolite.

\begin{tabular}{lll}
\hline Code & Treatment Temp, $\left({ }^{\circ} \mathrm{C}\right)$ & Treatment Time, $(\mathrm{h})$ \\
\hline T120t24 & 120 & 24 \\
T120t20 & 120 & 20 \\
T90t24 & 90 & 24 \\
T90t20 & 90 & 20 \\
T90t15 & 90 & 15 \\
T90t10 & 90 & 10 \\
T70t20 & 70 & 20 \\
\hline
\end{tabular}

and mineral phases not stable at high temperature [9]. The loss of ignition of rice husk ash in this experiment was $5.15 \%$ which corresponds to the removal of moisture and the coexisting unburned carbon from ash.

The X-ray diffraction patterns of rice husk ash and zeolitic products showed in Fig. 1. The result confirms the presence of the main constituent of $\mathrm{SiO}_{2}$ with crystalline type of quartz and cristobalite for rice husk ash. The result also shows the crystalline phases identified for each zeolite sample. The broad peak between $2 \theta$ of $21-37^{\circ}$ implied the presence of amorphous phase of carbon and silica as shown in Fig. 1a. Numerous peaks between $2 \theta$ of $6-34^{\circ}$ implied the presence of zeolite $\mathrm{X}$ as marked in Fig. 1b. The zeolite $\mathrm{X}$ (PDF card No. 38-0237) as shown in Fig. 1b was formed at the heating temperature of $90{ }^{\circ} \mathrm{C}$ to $120{ }^{\circ} \mathrm{C}$ for 20 to $24 \mathrm{~h}$ with the $\mathrm{SiO}_{2} / \mathrm{Al}_{2} \mathrm{O}_{3}$ molar ratio of 2.0. $\mathrm{SiO}_{2} / \mathrm{Al}_{2} \mathrm{O}_{3}$ molar adjustment was done by adding $\mathrm{Al}$ source to favor the formation of zeolite X. Quartz and

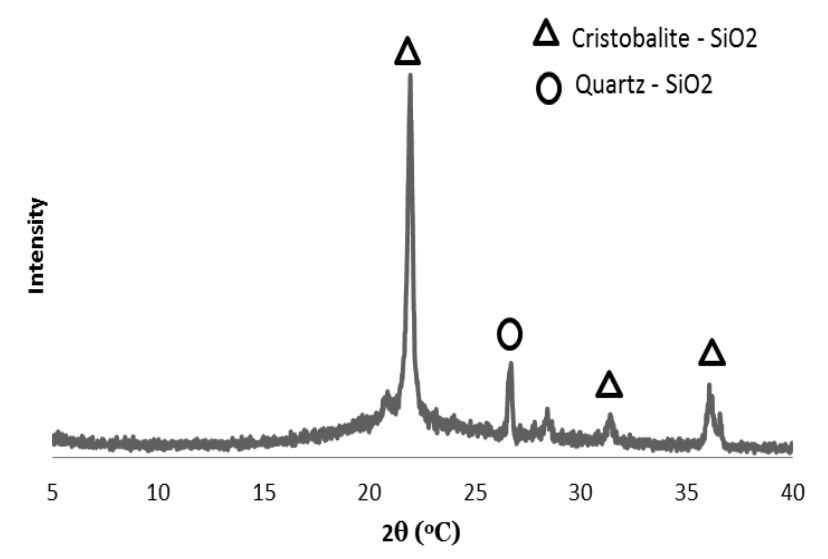

(a) cristobalite disappeared completely due to the mixing step, because these compounds can easily be dissolved for zeolite formation in the later stage of hydrothermal synthesis.

Morphological analysis of raw rice husk ash and zeolite $\mathrm{X}$ performed by the SEM (scanning electron micrographs) is showed in Fig. 2. It was observed that the surface of raw rice husk ash seemed to be rough with holes on it (Fig. 2a). On the other hand, the zeolite $\mathrm{X}$ shown the typical octahedral particle shape (Fig. 2b). The surface area of raw rice husk ash and synthesized zeolite was $11.08 \mathrm{~m}^{2} / \mathrm{g}$ and $703.2 \mathrm{~m}^{2} / \mathrm{g}$, respectively. The cation exchange capacity of synthesized zeolite $X$ was $503 \mathrm{meq} / 100 \mathrm{~g}$ and possessed the larger pore size of $0.74 \mathrm{~nm}$. Therefore, the synthesized zeolite can be used as good cation exchangers. A preliminary test showed that the synthesized zeolite from rice husk ash presented high adsorption capacity of $\mathrm{Cd}^{2+}[9]$.

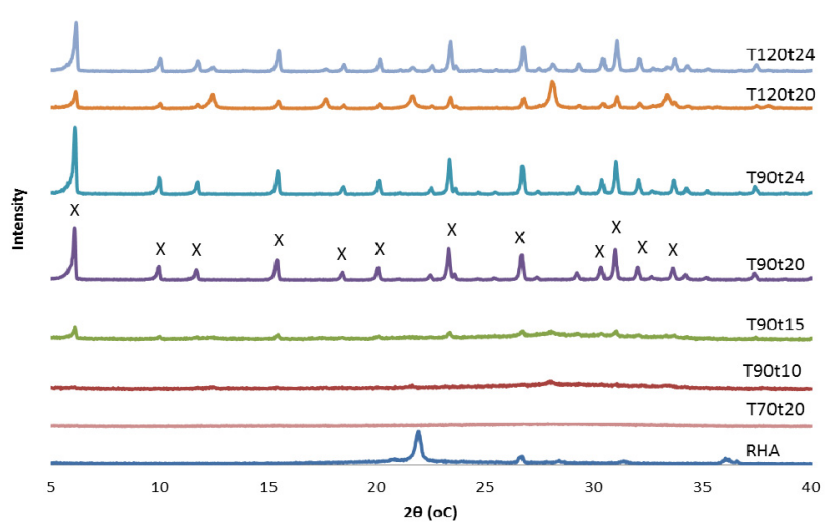

(b)

Fig. 1 XRD pattern of (a) raw rice husk ash from power plant; (b) comparison between raw rice husk ash and zeolitic materials. 


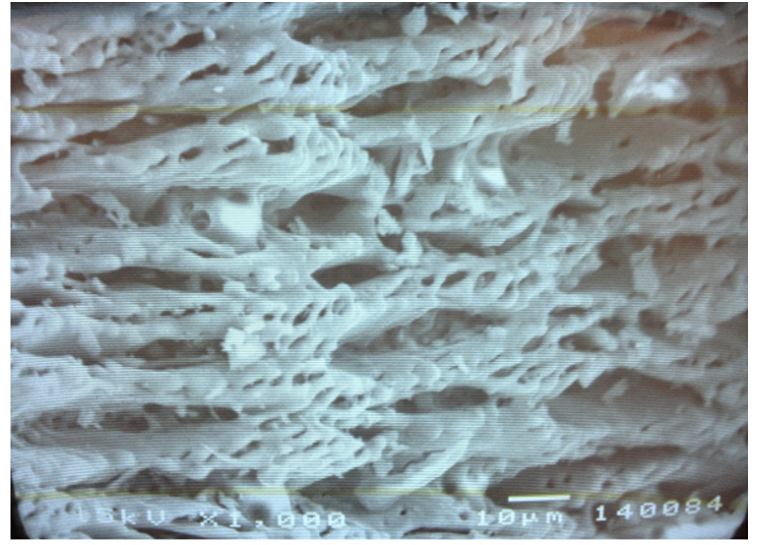

(a)

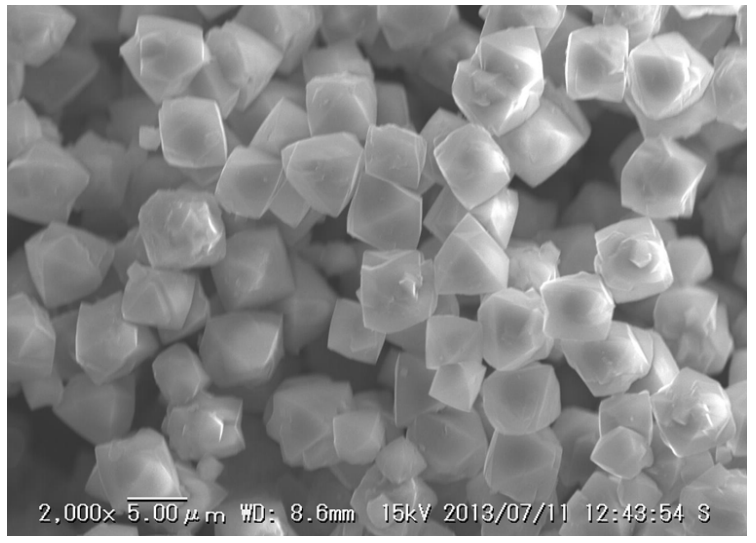

(b)

Fig. 2 SEM micrographs of (a) raw rice husk; (b) zeolite synthesized using the rice husk ash as a silica source synthesized by hydrothermal reaction at 90 to $120{ }^{\circ} \mathrm{C}$ for 10 to $24 \mathrm{~h}$.

\section{Conclusion}

The rice husk ash waste from power plant in Thailand can be used for synthesized zeolite $\mathrm{X}$ by using it as silica source by employing alkali fusion and then extraction with residue removal followed by hydrothermal treatment. Zeolite $\mathrm{X}$ was formed at 90 to $120^{\circ} \mathrm{C}$ hydrothermal treatment temperatures for 20 to $24 \mathrm{~h}$ by adjusting $\mathrm{Si} / \mathrm{Al}$ molar ratio to 2.0. The surface area of synthesized zeolite $\mathrm{X}$ was increased from 11.08 to $703.2 \mathrm{~m}^{2} / \mathrm{g}$ comparing with raw rice husk and the cation exchange capacity of $503 \mathrm{meq} / 100 \mathrm{~g}$ was obtained. From this result, synthesized zeolite has the potentiality to be used as ion exchangers.

\section{Acknowledgements}

The authors wish to gratefully acknowledge budget and equipment support from the Department of International Development Engineering, Tokyo Institute of Technology, Japan and the financial support from AUN/SEED-Net program. Roi-Et Green power plant, Thailand is also acknowledged for kindly rice husk ash providing.

\section{References}

[1] Thuadaij, P., and Nuntiya A. "Synthesis of Na-x Hydrate Zeolite form Fly Ash and Amorphous Silica from Rice
Husk Ash by Fusion with Caustic Soda Prior to Incubation." Presented at the International Conference on Chemistry and Chemical Process IPCBEE 10: 69-74..

[2] Ismail, H., Nasaruddin, M. N., and Rozman, H. D. 1999. "The Effect of Multifunctional Additive in White Rice Husk Ash Filled Natural Rubber Compounds.” Eur Polym J. 3: 1429-37.

[3] Huang, J. Y. "Beneficial Use of Fly Ash." Michigan Technological University.

[4] Tanaka, H., Eguchi, H., Fujimoto, S., and Hino, R. 2006. "Two-step Process for Synthesis of a Single Phase Na-A Zeolite from Coal Fly Ash by Dialysis." Fuel. 85: 1329-34.

[5] Tanaka, H., and Fujii, A. 2009. "Effect of Stirring on the Dissolution of Coal Fly Ash and Synthesis of Pure-form Na-A and -X Zeolite by Two-step Process." Advanced Powder Technology 20: 473-9.

[6] Machado, N. R. C. F., and Miotto, D. M. M. 2005. "Synthesis of Na-A and -X Zeolite from Oil Shale Ash." Fuel. 84: 2289-94.

[7] Purnomo, C. W., Salim, C., and Hinode, H. 2012. "Synthesis of Pure $\mathrm{Na}-\mathrm{X}$ and Na-A Zeolite form Bagasseaa Fly Ash." Microporous and Mesoporous Materials 162: 6-13.

[8] Ghasemi, Z., and Younesi, H. 2011. "Preparation and Characterization of Nanozeolite NaA from Rice Husk at Room Temperature without Organic Additives.” Journal of Nanomaterials 1-8.

[9] Juliana, de C. I., Denise, A. F., Fernando, S. dos S., and Shaobin, W. 2012. "Characteristics of Brazilian Coal Fly Ashes and Their Synthesized Zeolites.” Fuel Processing Technology 97: 38-44. 